\title{
Framing education on headache disorders into the Global Burden of Disease Study 2010. The European Headache Federation stands ready
}

\author{
Paolo Martelletti ${ }^{1 *}$, Dimos-Dimitrios Mitsikostas ${ }^{2}$, Christian Lampl $^{3}$, Zaza Katsarava ${ }^{4}$, Vera Osipova ${ }^{5}$, \\ Koen Paemeleire ${ }^{6}$, Lars Edvinsson ${ }^{7}$, Aksel Siva ${ }^{8}$, Dominique Valade ${ }^{9}$, Timothy J Steiner ${ }^{10}$ and Rigmor H Jensen ${ }^{11}$
}

\author{
Abstract \\ Framing education on headache disorders into the Global Burden of Disease Study 2010. The European Headache \\ Federation stands ready.
}

\section{Start-up for a new education on headache disorders after Global Burden of Disease Study 2010}

The Global Burden of Disease Study 2010 (GBD 2010), recently published in The Lancet [1], has marked new standards for all scientific societies, NGOs and patients' associations that gravitate towards headache disorders. These standards, dictated not only by the new migraine ranking but also by the appearance of tension-type headache, confirm headache in the top ten causes of global disability, in the top three ranking of global prevalence of disease and at the top of all neurological disorders as causes of years lived with disability. All this has been achieved despite the unjustified absence of medicationoveruse headache from GBD 2010. The fundamentals of these results are built on the hard-working epidemiological activity of the Neurologic Disorders Expert Group in Headache for GBD 2010, and Lifting The Burden (LTB) [2] which, on the basis of data carefully gathered (and featured in the Atlas of Headache Disorders and Resources in the World 2011 [3,4]), has then offered to GBD 2010 the headache-specific part of this cultural giant of modern medicine.

What is then the bond between the results therein included in this immense survey, correlated to the terms disability, sequelae, disability states, years lived with disability, impairments, and the European Headache Federation

\footnotetext{
* Correspondence: paolo.martelletti@uniroma1.it

${ }^{1}$ Department of Clinical and Molecular Medicine, Sapienza University of Rome, Sant'Andrea Hospital, Via di Grottarossa 1035, 00189, Rome, Italy Full list of author information is available at the end of the article
}

(EHF)? It is explicit in the message: "The principal findings, namely that mental health [impairments] ..... need urgent policy responses, are well established. Monitoring progress in reducing the effect of these, and other major contributors to health loss, is as important for improving population health as monitoring progress against the leading causes of death." In the strategy for achieving this in headache, physician education is a sine qua non $[3,4]$, upon which quality of care and any multiplicity of structures dedicated to the control of headache depend.

\section{European Headache Federation educational response}

EHF takes pride from its long history of education on primary headache disorders, integral to its mission, "Educate Europe about Headache". This purpose has been continuously pursued since its foundation over 30 years ago, across both Central and Eastern Europe. Its educational activities have been conducted through the residential EHF Headache Schools, commenced in 2002, and through the more recent distance-learning Video Conference Courses, commenced in 2009. We must also mention the aids offered by EHF in conjunction with LTB and WHO in the management of the most common types of primary headache, the European principles of management of common headache disorders in primary care [5], specifically aimed at general practitioners. The efficient penetration of these guidelines has been facilitated by their Italian, Portuguese and Russian translations freely available on the EHF website (www. ehf-org.org/). 
EHF has also cared about the other, high-academic end of education in headache, through its collaboration with Sapienza University of Rome. The Master in Headache Medicine course, held each year for ten years at Sapienza University of Rome, has been endorsed by EHF since the Academic Year 2005-2006, training a large number of specialists from various European countries and many other geographical areas in the world (http:// w3.uniroma1.it/headache) [6,7]. This initiative has allowed the creation of a headache cultural chain following the consolidated train-the-trainer method as an achievable foundation for global education [8]. Once trained as headache specialists, physicians will become trainers, offering education in this field to other healthcare providers in their own countries. In this way they will give life to the cultural chain, raising awareness wherever they go of headache, its burden and its medical control [9].

EHF has always strongly promoted educational collaborations with other important European Societies, such as European Federation of Neurological Societies (EFNS) and European Federation of Internal Medicine (EFIM). This last collaboration produced a Joint Symposium dedicated to Emergency Headache, with its clinically evident multidisciplinary characteristics and representing $4 \%$ of all admissions to the emergency departments of Europe [10]. Recently, the historical partnership between EHF and LTB has been enriched by an ad hoc partnership with the European Federation of IASP Chapters (EFIC), creating a Joint Task Force on Headache, which is already active in educating pain physicians and headache experts in some particular headache models.

A further educational product of EHF is the EHF Headache Series, pertinent monographs owned by EHF and to be published by Springer, which will cover the emerging sectors of headache science and education.

\section{Cultural liberalism in headache education allows a better future for headache patients}

It is therefore clear that GBD 2010 has found EHF operatively efficient to conduct its educational role in Europe, ready to further the dissemination of fundamental skills in this area of clinical medicine. This position and readiness stand opposite to protectionist selfpreservation fostered by an oligarchic culture, and bring new hope to patients who are not yet adequately treated or even yet diagnosed [11].

These fundamental rules of cultural liberalism and collaboration with like-minded neighbouring societies must lead us to set EHF's educational priorities. Such cultural openness is neither a sign of captatio benevolentiae nor a wish for colonization. Headache disorders are and always will be in a multidisciplinary and transversal area, where only those who are capable of integration and development, as opposed to exclusion and disqualification, will achieve and produce positive effects for the immense civil society who need them - for migraine alone, a billion people affected worldwide.

In fact, to produce new evidence in basic sciences and turn it into new molecules or devices for headache has very partial utility, if it does not reach most patients [12]. The use of triptans by only a small minority of people with migraine is exemplary of such failure, and should be a warning. Without better and larger structures dedicated to headache health-care service delivery $[13,14]$, and a concerted educational effort to train the large number of physicians these services require [13-15], few people will benefit, and not necessarily those most in need; the majority will remain without diagnosis and a proper treatment, carrying an impressive personal burden and contributing to that of society, and with not much hope for change.

We must all shrink from this, and reject the closed, exclusive cultural clubs that promise nothing else, obstinately pervaded by ancient self-referenced protectionism.

\section{Competing interests}

The authors declare that they have no competing interests related to this Editorial.

\section{Authors' contributions}

PM, TJS, RHJ drafted the manuscript. All authors read and approved the final manuscript.

\section{Acknowledgments}

All Authors (except TJS) are Trustees and Directors of the European Headache Federation (EHF). TJS is a founding member and past-President of EHF. The Authors declared no COI related to the contents of this Editorial.

\section{Author details}

${ }^{1}$ Department of Clinical and Molecular Medicine, Sapienza University of Rome, Sant'Andrea Hospital, Via di Grottarossa 1035, 00189, Rome, Italy. 2Department of Neurology, Athens Naval Hospital, Athens, Greece. ${ }^{3}$ Department of Neurology and Pain Medicine, Konventhospital Barmherzige Brüder, Linz, Austria. ${ }^{4}$ Department of Neurology University of Duisburg-Essen, Essen and Department of Neurology, Evangelisches Krankenhaus Unna, Unna, Germany. ${ }^{5}$ Department of Neurology and Clinical Neurophysiology, First Sechenov Moscow State Medical University, Moscow, Russia.

${ }^{6}$ Department of Neurology, Ghent University Hospital, Ghent, Belgium. ${ }^{7}$ Department of Internal Medicine, University Hospital, Lund, Sweden. ${ }^{8}$ Department of Neurology, Cerrahpasa School of Medicine, Istanbul University, Istanbul, Turkey. ${ }^{9}$ Hôpital Lariboisière, Paris, France. ${ }^{10}$ Department of Neuroscience, Norwegian University of Science and Technology, Trondheim, Norway. ${ }^{11}$ Danish Headache Center, Department of Neurology, University of Copenhagen, Glostrup Hospital, Copenhagen, Denmark.

Received: 30 April 2013 Accepted: 4 May 2013

Published: 10 May 2013

\section{References}

1. Vos T, Flaxman AD, Naghavi M, Lozano R, Michaud C, Ezzati M, Shibuya K, Salomon JA, Abdalla S, Aboyans V, Abraham J, Ackerman I, Aggarwal R, Ahn SY, Ali MK, Alvarado M, Anderson HR, Anderson LM, Andrews KG, Atkinson C, Baddour LM, Bahalim AN, Barker-Collo S, Barrero LH, Bartels DH, Basáñez MG, Baxter A, Bell ML, Benjamin EJ, Bennett D (2012) Years lived with disability (YLD) for 1160 sequelae of 289 diseases and injuries 1990-2010: a systematic analysis for the Global Burden of Disease Study 2010 Lancet 380:2163-2196 
2. Steiner TJ, Stovner L, Birbeck GL (2013) Migraine: the seventh disabler. J Headache Pain 14:1

3. World Health Organization and Lifting The Burden (2011) Atlas of headache disorders and resources in the world 2011. World Health Organization, Genève. available at http://www.who.int/mental_health/ management/atlas_headache_disorders/en/

4. Martelletti P, Birbeck GL, Katsarava K, Jensen RH, Stovner LJ, Steiner TJ (2013) The Global Burden of Disease Survey 2010, Lifting The Burden and thinking outside-the-box on headache disorders. J Headache Pain 14:13

5. Steiner $T$ J, Paemeleire $K$, Jensen R, Valade D, Savi L, Lainez MJ, Diener HC, Martelletti $P$, Couturier EG, on behalf of European Headache Federation and Lifting The Burden: The Global Campaign to Reduce the Burden of Headache Worldwide (2007) European principles of management of common headache disorders in primary care. J Headache Pain 8(Suppl 1):S3-S47

6. Martelletti P (2005) Academic specialist education in headache medicine. Next move for the headache community. J Headache Pain 6:103-104

7. Martelletti $P$ (2007) Headache medicine: academic teaching in Europe. The Sapienza university Master's degree. Headache 47:1224-1225

8. Martelletti P, Haimanot RT, Láinez MJ, Rapoport AM, Ravishankar K, Sakai F, Silberstein SD, Vincent M, Steiner TJ (2005) The global campaign (GC) to reduce the burden of headache worldwide. The international team for specialist education (ITSE). J Headache Pain 6:261-263

9. Martelletti P, Steiner T (2010) Headache disorders: building specialist education. In: Olesen J, Ramadan N (ed) Headache care, research and education worldwide, 17th edition. Oxford University Press, Oxford, pp 173-178

10. Licata G, Lindgren S, Diener HC, Martelletti $P$ (2008) Headache and emergency medicine: sharing a language for a common project. Intern Emerg Med 3(Suppl 1):S1-S2

11. Cevoli S, D'Amico D, Martelletti P, Valguarnera F, Del Bene E, De Simone R, Sarchielli P, Narbone M, Testa L, Genco S, Bussone G, Cortelli P (2009) Underdiagnosis and undertreatment of migraine in Italy: a survey of patients attending for the first time 10 headache centres. Cephalalgia 29:1285-1293

12. Steiner TJ (2013) Headache in the world: public health and research priorities. Expert Rev Pharmacoecon Outcomes Res 13:51-57

13. Steiner $T J$, Antonaci $F$, Jensen $R$, Lainez $M J$, Lanteri-Minet $M$, Valade $D$, on behalf of European Headache Federation and Lifting The Burden: the Global Campaign against Headache (2011) Recommendations for headache service organisation and delivery in Europe. J Headache Pain 12:419-426

14. Antonaci F, Valade D, Lanteri-Minet M, Láinez JM, Jensen R, Steiner TJ, on behalf of European Headache Federation and Lifting The Burden: the Global Campaign to Reduce the Burden of Headache Worldwide (2008) Proposals for the organisation of headache services in Europe. Intern Emerg Med 3(Suppl 1):S25-S28

15. Jensen R, Mitsikostas DD, Valade D, Antonaci F (2010) Guidelines for the organization of headache education in Europe: the headache school II. J Headache Pain 11:161-165

doi:10.1186/1129-2377-14-41

Cite this article as: Martelletti et al:: Framing education on headache disorders into the Global Burden of Disease Study 2010. The European Headache Federation stands ready. The Journal of Headache and Pain 2013 14:41.

\section{Submit your manuscript to a SpringerOpen ${ }^{\circ}$ journal and benefit from:}

- Convenient online submission

- Rigorous peer review

- Immediate publication on acceptance

- Open access: articles freely available online

- High visibility within the field

- Retaining the copyright to your article

Submit your next manuscript at $\gg$ springeropen.com 